\title{
QTL Analysis for Resistance to Blast Disease in U.S. Weedy Rice
}

\author{
Yan Liu, ${ }^{1,2}$ Xinshuai Qi, ${ }^{3}$ Dave R. Gealy, ${ }^{2}$ Kenneth M. Olsen, ${ }^{3}$ Ana L. Caicedo, ${ }^{4}$ and Yulin Jia ${ }^{2}$ \\ ${ }^{1}$ Rice Research and Extension Center, University of Arkansas, Stuttgart 72160, U.S.A.; ${ }^{2}$ United States Department of \\ Agriculture-Agricultural Research Service Dale Bumpers National Rice Research Center, Stuttgart, AR 72160, U.S.A.; \\ ${ }^{3}$ Department of Biology, Washington University in St. Louis, St. Louis 63130-4899, U.S.A.; and ${ }^{4}$ Biology Department, University \\ of Massachusetts Amherst, 01003, U.S.A.
}

Submitted 20 February 2015. Accepted 2 March 2015.

Understanding the genetic architecture of adaptation is of great importance in evolutionary biology. U.S. weedy rice is well adapted to the local conditions in U.S. rice fields. Rice blast disease is one of the most destructive diseases of cultivated rice worldwide. However, information about resistance to blast in weedy rice is limited. Here, we evaluated the disease reactions of 60 U.S. weedy rice accessions with 14 blast races, and investigated the quantitative trait loci (QTL) associated with blast resistance in two major ecotypes of U.S. weedy rice. Our results revealed that U.S. weedy rice exhibited a broad resistance spectrum. Using genotyping by sequencing, we identified 28 resistance QTL in two U.S. weedy rice ecotypes. The resistance QTL with relatively large and small effects suggest that U.S. weedy rice groups have adapted to blast disease using two methods, both major resistance $(R)$ genes and QTL. Three genomic loci shared by some of the resistance QTL indicated that these loci may contribute to no-race-specific resistance in weedy rice. Comparing with known blast disease $R$ genes, we found that the $R$ genes at these resistance QTL are novel, suggesting that U.S. weedy rice is a potential source of novel blast $\boldsymbol{R}$ genes for resistant breeding.

Understanding the genetic basis of adaptation has been a fundamental and challenging subject in evolutionary biology. Studies on the identification of quantitative trait loci (QTL) or candidate genes underlying the adaptive traits and the extent of phenotypic adaptation have been emphasized as a preliminary step to gain insight into the genetic basis of adaptation. Recently, several studies in Arabidopsis thaliana and humans have provided some insights into novel candidate genes and pathways that might be involved in adaptation to different environments using genome-wide association mapping and QTL mapping (Ágren et al. 2013; Anderson et al. 2013; Dittmar et al. 2014; Oakley et al. 2014; Scheinfeldt and Tishkoff 2013). Studies of the genes which control the adaptive traits will provide insights into the molecular mechanism of adaptation. However, due to the lack of a genomic perspective, it had been a daunting task to

Corresponding author: Y. Jia; Telephone: +1.870 .672 .9300 ext. 229; Fax: +1.870.673.7581; E-mail: yulin.jia@ars.usda.gov

*The $e$-Xtra logo stands for "electronic extra" and indicates that four supplementary tables are published online.

This article is in the public domain and not copyrightable. It may be freely reprinted with customary crediting of the source. The American Phytopathological Society, 2015. study the genetic basis of the adaptive traits. With the advances of the next generation DNA sequencing, Pritchard and Di Rienzo (2010) proposed that polygenic adaptation may be an important genetic basis for many adaptive events in natural human populations. Daub et al. (2013) found evidence for polygenic adaptation to pathogens in the human genome with the genomewide single-nucleotide polymorphism (SNP) data set. However, knowledge regarding the genetic basis of adaptation in invasive and nonmodel species is still limited.

Agricultural weeds are problematic invasive species and have been evolving in agricultural environments for thousands of years. Several hypotheses have been proposed that agricultural weeds may have evolved through three pathways: (i) colonization of wild species to the local environment, (ii) dedomestication of crop plants, and (iii) weed-crop hybridization (Vigueira et al. 2013). However, the genetic basis of adaptive evolution in agricultural weeds is still a largely unexplored area although, recently, inroads are being made into understanding the evolution of weedy rice (Oryza sativa). As an invasive species, weedy rice is a serious agricultural pest that aggressively invades rice fields in the United States and worldwide. Weedy rice is difficult to control by weeding and herbicides because it closely mimics the invaded rice crops. In the United States, weedy rice competes with cultivated rice in approximately $30 \%$ of rice fields, and exhibits many adaptive traits such as increased seed shattering and dormancy, high growth rate and high phenotypic diversity (Delouche et al. 2007; Thurber et al. 2010). Under certain conditions, weedy rice can reduce crop yield up to $80 \%$ (Estorninos et al. 2005). In the United States, there are two major different ecotypes of weedy rice, including black hull awned (BHA) weedy rice and straw hull awnless $(\mathrm{SH})$ weedy rice. Studies on the genetic composition of U.S. weedy rice ecotypes suggest that BHA and SH weeds may have originated from cultivated Asian aus and indica rice subgroups, respectively, which have never been cultivated in the United States (Reagon et al. 2010). U.S. weedy rice is believed to have been introduced to the continent in contaminated seed (Delouche et al. 2007) following a process of dedomestication of cultivated rice in Asia. Because it is similar to cultivated rice, weedy rice provides a good system to study the genetic basis of local adaptive evolution in invasive species (Anderson et al. 2011).

Blast disease of rice is one of the most devastating diseases caused by the filamentous ascomycete fungal pathogen Magnaporthe oryzae, which threatens rice production in the southern United States and worldwide. Similar to cultivated rice, invasive weedy rice is also attacked by $M$. oryzae. Rice is one of the most widely grown food crops in the world and $M$. oryzae is a highly mutable pathogen (Valent and Chumley 1994). Therefore, similar to rice, the weedy rice-M. oryzae 
pathosystem provides an excellent model system to study the genetic basis of adaptation between weedy rice and a changeable environment. To date, over 100 major blast resistance $(R)$ genes and 350 QTL have been identified in cultivated rice and its wild rice relatives (Ballini et al. 2008; Liu et al. 2013, 2015; Sharma et al. 2012; Xu et al. 2014). $R$ genes in weedy rice may be obtained through gene flow from cultivated varieties or via shared inheritance from cultivated ancestors through a process of dedomestication. Blast disease resistance to $M$. oryzae was observed among weedy rice genotypes (Lee et al. 2009, 2011); however, the genetic mechanisms of phenotypic adaptation to rice pathogens in U.S. weedy rice has not been explored.

In the present study, our goal was to investigate the QTL associated with resistance to rice blast disease, which will provide significant insights into the genetic basis of blast resistance in U.S. weedy rice, combining contemporary genotyping by sequencing (GBS) technology and classical quantitative genetics techniques. The objectives of this study were to (i) evaluate the disease reactions of U.S. weedy rice to rice blast pathogens, (ii) investigate the blast resistance QTL in U.S. weedy rice, and (iii) predict the candidate $R$ genes in U.S. weedy rice.

\section{RESULTS}

Blast disease evaluation of weedy rice ecotypes.

The disease reactions of each weedy rice accession were observed in the greenhouse and listed in Table 1. Cluster analysis of these weedy rice accessions based on their reactions to 14 blast races was performed with hierarchical cluster analysis of IBM SPSS Statistics, version 12.0 (Fig. 1). On the basis of the disease resistance spectrum, all of the weedy rice accessions were clustered into four groups (group I to IV) (Fig. 1; Supplementary Table $\mathrm{S} 1)$. The weedy rice accessions in different groups exhibited different disease resistance to 0 to 10 blast races (Table 1). In all, 42 weedy rice accessions falling into group I were the least resistant, with 17 accessions being susceptible to all 14 races tested and 25 accessions being resistant to 1 to 4 races of $M$. oryzae. Moreover, the resistance in group I was partial and the disease score was 1 or 2, except for PI653431, which showed complete resistance to the blast race IC17 (Table 1), with a score of 0 . However, weedy rice ecotypes, falling into group II and III, exhibited a broad-spectrum resistance, including complete resistance or partial resistance to 3 to 10 blast races, with a disease resistance score of 0,1 , or 2 . The weedy rice AR-1996-01, a crop-weed hybrid progeny (Gealy et al. 2002), grouped into group IV and exhibited the broadest complete resistance to 10 blast races, with a resistance score of 0 . AR-1996-01 exhibited susceptibility to only four races (IH1, IB54, IC1, and IB33) of $M$. oryzae. The virulence rate, used to compare the virulence of each race in this study, is the percentage of the number of genotypes which were compatible with the race/the number of genotypes which were tested with the race. The three most virulent of the 14 blast races were IB45, IA45, and IB33, which were compatible with 59 weedy rice ecotypes, with a virulence rate of $98.3 \%$. Of these three races, IB45 and IA45 were only incompatible with the genotype AR-1996-01 and IB33 was incompatible with PI653413 (Table 1). IA1, IC1, and IB54 were also highly virulent to weedy rice accessions and the virulence rates were 96.7, 95, and 93.3\%, respectively. However, race IE1 was the least virulent to weedy rice, with a virulence rate of 48.3\%. Races IC17, ID1, IH1, IB49, IE1K, IB1, and IG1 of $M$. oryzae were less virulent to weedy rice ecotypes, and the virulence rate was 60 to $83.3 \%$.

\section{Blast disease evaluation}

of two recombinant inbred line populations.

According to the disease reactions of weedy rice accessions to 14 blast races, RR20 (PI653419), a representative BHA weedy rice ecotype and a parent of the $\mathrm{B}$ recombinant inbred line (RIL) population, showed partial resistance to blast races IE1, E1K, and IC17 and was partially susceptible to IC1, ID1, and IB33. RR9 (PI653435), a representative SH weedy rice ecotype and a parent of the S RIL population, was partially susceptible to ID1 and IC17 of M. oryzae (Table 1; Fig. 2). Based on the differences of the disease reactions of three parental lines Dee Geo Woo Gen (DGWG), RR20, and RR9, IE1, IE1K, IC17, IC1, and ID1 were selected for blast disease evaluation of the B population, and IC17 and ID1 were selected for disease evaluation of the $\mathrm{S}$ population. The phenotypic data for the two RIL populations are listed in Supplementary Tables S2 and S3. The distributions of disease reactions of RILs of the two populations are shown in Figure 3.

\section{Mapping of blast resistance QTL.}

Using GBS, 6,513 SNPs were identified in the $S$ population and 14,382 SNPs in the B population (see Materials and Methods). The high-resolution linkage map of each population was constructed. The genetic map was 1,524 centimorgans (cM) for the $\mathrm{S}$ population and $1,536 \mathrm{cM}$ for the $\mathrm{B}$ population, with an average intermarker distance of $0.234 \pm 0.06$ and $0.107 \pm 0.01$, respectively.

Using the S population, six resistance QTL were identified in RR9 using the blast races IC17 and ID1 of M. oryzae (Table 2; Fig. 4). They were named $q B R 4.1 s, q B R 4.2 s, q B R 5.1 s, q B R 11.1 s$, $q B R 12.1 s$, and $q B R 12.2 s$. QTL $q B R 4.1 s, q B R 5.1 s$, and $q B R 12.1 s$ were identified with blast race IC17. The QTL $q B R 4.1 s$, accounting for $0.44 \%$ of the disease variance, was identified by the SNP S4_31225606 and was located at a genomic interval of $9.12 \mathrm{cM}$ on chromosome 4 , with a logarithm of the odds (LOD) value of 3.90. The QTL $q B R 5.1 s$, accounting for $0.72 \%$ of the disease variance, was identified by S5_258527 and was located at a genomic interval of $3.43 \mathrm{cM}$ on chromosome 5, with an LOD of 4.20. A major resistance QTL, $q B R 12.1 s$, accounting for $70.29 \%$ of the disease variance, was identified by S12_11312938 and was located at a relatively small genomic interval of $2.74 \mathrm{cM}$ on chromosome 12, with an LOD of 52.89. There was no additive effect to disease variance among $q B R 4.1 s, q B R 5.1 s$, and $q B R 12.1 s$. However, $q B R 4.2 s, q B R 11.1 s$, and $q B R 12.2 s$ were identified with the blast race ID1. Based on their linkage and flanking SNP markers, $q B R 4.2 s$, accounting for $5.6 \%$ of the disease variance, was mapped on chromosome 4 and located into the same genomic region with $q B R 4.1 s$; and $q B R 12.2 s$, accounting for $68.04 \%$ of the disease variance, was identified by the same SNP marker as $q B R 12.1 s$ on chromosome 12 and had an overlap interval of $2.74 \mathrm{cM}$ with $q B R 12.1 \mathrm{~s}$. These results indicated that resistance QTL $q B R 4.1 s$ and $q B R 4.2 s$ may be located at the same genomic region and controlled by the same $R$ genes on chromosome 4, and that $q B R 12.1 s$ and $q B R 12.2 s$ may be located at the same genomic region on chromosome 12 and may be controlled by the same $R$ genes (Table 2; Fig. 4). The QTL qBRI1.1s, accounting for $2.17 \%$ of the disease variance, was identified by S11_25150111 and located at a genomic interval of $6.3 \mathrm{cM}$ on chromosome 11, with an LOD of 3.59. There was no additive effect to disease variance among $q B R 4.2 s, q B R 11.1 s$, and $q B R 12.2 s$.

Using the B population, 22 resistance QTL were identified in RR20 with six blast races, including IC17, ID1, IB33, IC1, IE1K, and IE1 (Table 2; Fig. 4). Using race IC17, three resistance QTL ( $q B R 4.1 b, q B R 4.2 b$, and $q B R 12.1 b)$ were identified. $q B R 4.1 b$, accounting for $4.85 \%$ of the disease variance, was mapped to a genomic interval of $0.39 \mathrm{cM}$ on chromosome 4, with an LOD of 18.52. qBR4.2b, accounting for $13.57 \%$ of the disease variance, was mapped to a genomic interval of 5.75 $\mathrm{cM}$ on chromosome 4, with the LOD of 9.55. $q B R 12.1 b$, accounting for $2.71 \%$ of the disease variance, was mapped to a genomic interval of $1.93 \mathrm{cM}$ on chromosome 12, with an LOD 
of 20.98. The additive effect on disease variance of $q B R 4.2 b$ and $q B R 12.1 b$ was $1.96 \%$.

Using race ID1, two resistance QTL were identified. The QTL $q B R 4.3 b$ was identified by the same SNP marker as $q B R 4.2 b$ and was mapped to a $0.26 \mathrm{cM}$ genomic interval on chromosome 4, with an LOD of 14.19, which accounted for $24.68 \%$ of the disease variance to race ID1. The QTL $q B R 12.2 b$ accounted for $25.58 \%$ of the disease variance and was mapped

Table 1. Blast disease resistance spectrum of 60 U.S. weedy rice accessions to 14 races of Magnaporthe oryzae

\begin{tabular}{|c|c|c|c|c|c|c|c|c|c|c|c|c|c|c|}
\hline \multirow[b]{2}{*}{ Accession ID $^{\mathbf{c}}$} & \multicolumn{14}{|c|}{ Rice blast races $^{b}$} \\
\hline & IH1 & IE1 & IE1K & IB1 & IB54 & IB45 & IG1 & IA45 & IB33 & IC17 & IA1 & IB49 & ID1 & IC1 \\
\hline AR01-1001-01 & 3 & 1 & 5 & 5 & 5 & 5 & 5 & 5 & 5 & 3 & 5 & 3 & 1 & 5 \\
\hline AR02-1002-02 & 3 & 2 & 5 & 5 & 4 & 5 & 5 & 5 & 5 & 3 & 5 & 3 & 3 & 5 \\
\hline AR01-1043 & 5 & 5 & 5 & 5 & 3 & 5 & 5 & 5 & 5 & 4 & 5 & 5 & 5 & 5 \\
\hline LA01-1047-01 & 0 & 3 & 3 & 1 & 5 & 5 & 1 & 5 & 5 & 0 & 3 & 1 & 1 & 3 \\
\hline MO01-1061 & 5 & 3 & 2 & 4 & 5 & 5 & 4 & 5 & 5 & 2 & 5 & 3 & 0 & 3 \\
\hline MO02-1073-02 & 3 & 2 & 5 & 5 & 5 & 5 & 5 & 5 & 5 & 3 & 5 & 3 & 3 & 5 \\
\hline MS02-1092-02 & 5 & 2 & 5 & 5 & 5 & 5 & 5 & 5 & 5 & 3 & 5 & 5 & 5 & 5 \\
\hline AR02-1099 & 5 & 3 & 5 & 5 & 5 & 5 & 5 & 5 & 5 & 3 & 5 & 5 & 3 & 5 \\
\hline MS-2001-1101 & 0 & 1 & 0 & 1 & 5 & 5 & 2 & 5 & 5 & 1 & 2 & 1 & 1 & 1 \\
\hline LA02-1105 & 1 & 2 & 5 & 3 & 5 & 5 & 3 & 5 & 5 & 3 & 5 & 1 & 1 & 3 \\
\hline AR01-1111-01 & 5 & 3 & 5 & 5 & 2 & 5 & 5 & 5 & 5 & 3 & 5 & 5 & 5 & 5 \\
\hline AR02-1120-02 & 5 & 2 & 5 & 5 & 5 & 5 & 5 & 5 & 5 & 3 & 5 & 3 & 3 & 5 \\
\hline LA01-1163-01 & 0 & 1 & 2 & 1 & 5 & 5 & 1 & 5 & 5 & 0 & 4 & 3 & 3 & 3 \\
\hline AR01-1183-01 & 5 & 3 & 5 & 5 & 5 & 5 & 5 & 5 & 5 & 3 & 5 & 5 & 5 & 5 \\
\hline MO01-1187 & 5 & 3 & 5 & 3 & 5 & 5 & 5 & 5 & 5 & 3 & 5 & 3 & 2 & 5 \\
\hline LA01-1190-01 & 2 & 2 & 5 & 4 & 5 & 5 & 4 & 5 & 5 & 3 & 3 & 2 & 3 & 5 \\
\hline MO-2001-1195 & 4 & 3 & 5 & 5 & 5 & 5 & 5 & 5 & 5 & 3 & 5 & 5 & 3 & 5 \\
\hline MO01-1199-01 & 3 & 3 & 5 & 5 & 5 & 5 & 5 & 5 & 5 & 3 & 5 & 3 & 4 & 5 \\
\hline MO02-1210-02 & 1 & 3 & 5 & 5 & 5 & 5 & 5 & 5 & 5 & 3 & 5 & 3 & 1 & 5 \\
\hline LA02-1243 & 0 & 2 & 0 & 2 & 5 & 5 & 2 & 5 & 5 & 1 & 3 & 1 & 1 & 3 \\
\hline MO02-1263 & 5 & 3 & 5 & 5 & 5 & 5 & 5 & 5 & 5 & 3 & 5 & 5 & 3 & 5 \\
\hline AR02-1271 & 5 & 5 & 5 & 5 & 5 & 5 & 5 & 5 & 5 & 3 & 5 & 3 & 5 & 5 \\
\hline MO02-1300-02 & 5 & 5 & 5 & 5 & 5 & 5 & 5 & 5 & 5 & 4 & 5 & 3 & 5 & 5 \\
\hline LA02-1312 & 5 & 5 & 5 & 5 & 5 & 5 & 5 & 5 & 5 & 5 & 5 & 3 & 5 & 5 \\
\hline MO02-1333-02 & 1 & 2 & 5 & 5 & 5 & 5 & 5 & 5 & 5 & 3 & 5 & 3 & 3 & 5 \\
\hline MO02-1344-02 & 4 & 2 & 5 & 5 & 5 & 5 & 5 & 5 & 5 & 5 & 5 & 3 & 2 & 5 \\
\hline MS02-1430 & 5 & 5 & 5 & 5 & 5 & 5 & 5 & 5 & 5 & 5 & 5 & 5 & 5 & 5 \\
\hline LA02-1431 & 1 & 1 & 3 & 3 & 2 & 5 & 3 & 5 & 5 & 1 & 5 & 2 & 3 & 5 \\
\hline LA95-12 & 0 & 0 & 3 & 4 & 3 & 5 & 3 & 5 & 5 & 3 & 5 & 3 & 0 & 3 \\
\hline LA95-13 & 3 & 2 & 3 & 3 & 2 & 5 & 2 & 5 & 5 & 3 & 3 & 1 & 2 & 3 \\
\hline LA95-14 & 2 & 2 & 0 & 0 & 4 & 5 & 1 & 4 & 5 & 0 & 5 & 1 & 0 & 3 \\
\hline MS96-8 & 0 & 2 & 2 & 2 & 3 & 5 & 3 & 5 & 5 & 1 & 5 & 1 & 0 & 2 \\
\hline AR-1996-01 & 5 & 0 & 0 & 0 & 4 & 0 & 0 & 0 & 5 & 0 & 0 & 0 & 0 & 3 \\
\hline PI653412 & 5 & 4 & 2 & 5 & 5 & 5 & 5 & 5 & 5 & 2 & 3 & 5 & 5 & 3 \\
\hline PI653413 & 5 & 0 & 1 & 3 & 2 & 5 & 0 & 5 & 1 & 1 & 5 & 5 & 3 & 3 \\
\hline PI653414 & 0 & 3 & 2 & 2 & 4 & 5 & 5 & 4 & 5 & 2 & 4 & 1 & 3 & 3 \\
\hline PI653415 & 5 & 1 & 1 & 3 & 5 & 3 & 5 & 5 & 5 & 1 & 5 & 3 & 3 & 5 \\
\hline PI653416 & 1 & 1 & 1 & 5 & 3 & 5 & 5 & 5 & 5 & 1 & 5 & 2 & 1 & 3 \\
\hline PI653417 & 3 & 0 & 1 & 2 & 3 & 5 & 5 & 5 & 5 & 1 & 3 & 1 & 1 & 3 \\
\hline PI653418 & 2 & 2 & 3 & 3 & 4 & 5 & 3 & 5 & 5 & 0 & 3 & 3 & 1 & 3 \\
\hline PI653419(RR20) & 5 & 2 & 1 & 5 & 5 & 5 & 5 & 5 & 3 & 2 & 5 & 5 & 3 & 3 \\
\hline PI653420 & 0 & 1 & 1 & 0 & 3 & 5 & 1 & 5 & 5 & 0 & 3 & 0 & 1 & 1 \\
\hline PI653421 & 5 & 2 & 2 & 3 & 5 & 5 & 3 & 5 & 5 & 1 & 5 & 3 & 3 & 3 \\
\hline PI653422 & 5 & 3 & 1 & 4 & 5 & 5 & 5 & 5 & 5 & 1 & 5 & 3 & 1 & 1 \\
\hline PI653424 & 5 & 3 & 3 & 5 & 5 & 5 & 5 & 5 & 5 & 5 & 5 & 5 & 3 & 3 \\
\hline PI653425 & 5 & 5 & 1 & 3 & 5 & 5 & 5 & 5 & 5 & 5 & 5 & 5 & 3 & 5 \\
\hline PI653426 & 2 & 2 & 3 & 5 & 3 & 5 & 4 & 5 & 5 & 3 & 5 & 5 & 1 & 5 \\
\hline PI653427 & 5 & 5 & 3 & 5 & 5 & 5 & 5 & 5 & 5 & 5 & 3 & 5 & 5 & 5 \\
\hline PI653428 & 5 & 4 & 5 & 5 & 5 & 5 & 5 & 5 & 5 & 1 & 5 & 5 & 4 & 4 \\
\hline PI653429 & 0 & 1 & 5 & 3 & 3 & 5 & 2 & 5 & 5 & 3 & 3 & 0 & 1 & 3 \\
\hline PI653430 & 5 & 3 & 2 & 5 & 5 & 5 & 5 & 5 & 3 & 2 & 5 & 3 & 5 & 3 \\
\hline PI653431 & 5 & 3 & 4 & 5 & 5 & 5 & 5 & 5 & 5 & 0 & 5 & 3 & 5 & 3 \\
\hline PI653432 & 5 & 5 & 5 & 5 & 5 & 5 & 5 & 5 & 5 & 3 & 5 & 3 & 3 & 5 \\
\hline PI653433 & 3 & 3 & 5 & 5 & 5 & 5 & 5 & 5 & 5 & 3 & 5 & 3 & 3 & 3 \\
\hline PI653434 & 5 & 2 & 5 & 5 & 5 & 5 & 5 & 5 & 5 & 3 & 5 & 3 & 2 & 5 \\
\hline PI653435(RR9) & 5 & 3 & 5 & 5 & 5 & 5 & 5 & 5 & 5 & 3 & 5 & 3 & 3 & 5 \\
\hline PI653436 & 5 & 5 & 5 & 5 & 5 & 5 & 5 & 5 & 5 & 3 & 5 & 3 & 3 & 5 \\
\hline PI653437 & 3 & 2 & 3 & 5 & 3 & 5 & 5 & 5 & 5 & 1 & 3 & 3 & 3 & 5 \\
\hline PI653438 & 5 & 1 & 5 & 5 & 5 & 5 & 5 & 5 & 5 & 4 & 5 & 5 & 3 & 5 \\
\hline PI653439 & 5 & 5 & 3 & 5 & 5 & 5 & 5 & 3 & 5 & 3 & 3 & 5 & 4 & 5 \\
\hline Virulence (\%) & 70 & 48.3 & 70 & 83.3 & 93.3 & 98.3 & 83.3 & 98.3 & 98.3 & 60 & 96.7 & 75 & 63.3 & 95 \\
\hline
\end{tabular}

\footnotetext{
a Blast disease was scored on a 0-to- 5 score scale. Weedy rice accessions with a score of 0 to 2 were considered as resistant and those with a score of 3 to 5 were considered susceptible. The evaluation of each race was conducted three times and the score of three reads with at least two appearances is listed in the table.

b Complete names of 14 races are as follows: IB33 (FL9), IC1 (BRFD-2F-2), IC17 (ZN57), IE1K (TM2), ID1 (ZN42), IB54 (isolate unnamed), IB49 (ZN61), IB1 (isolate unnamed), IA1 (BRFD-21-2), IG1 (ZN39), IE1 (ZN13), IB45 (isolate unnamed), IA45 (75L14), and IH1 (isolate unnamed).

${ }^{c}$ Weedy rice accession ID. Virulence of race (Virulence) is the percentage of the number of genotypes which were compatible with the race/the number of genotypes which were tested with the race.
} 
to a genomic interval of $2.49 \mathrm{cM}$ on chromosome 12 , with an LOD of 14.73. Using race IB33, four minor resistance QTL $(q B R 1.1 b, q B R 4.4 b, q B R 11.1 b$, and $q B R 12.3 b)$ were mapped on chromosomes $1,4,11$, and 12 , respectively. They accounted for $12.85 \%$ of the disease variance in RR20. Seven resistance QTL $(q B R 1.2 b, q B R 2.1 b, q B R 4.5 b, q B R 4.6 b, q B R 7.1 b$, $q B R 11.2 b$, and $q B R 12.4 \mathrm{~b})$ were identified and mapped on six chromosomes-, 2, 4, 7, 11, and 12-using race IC1 and

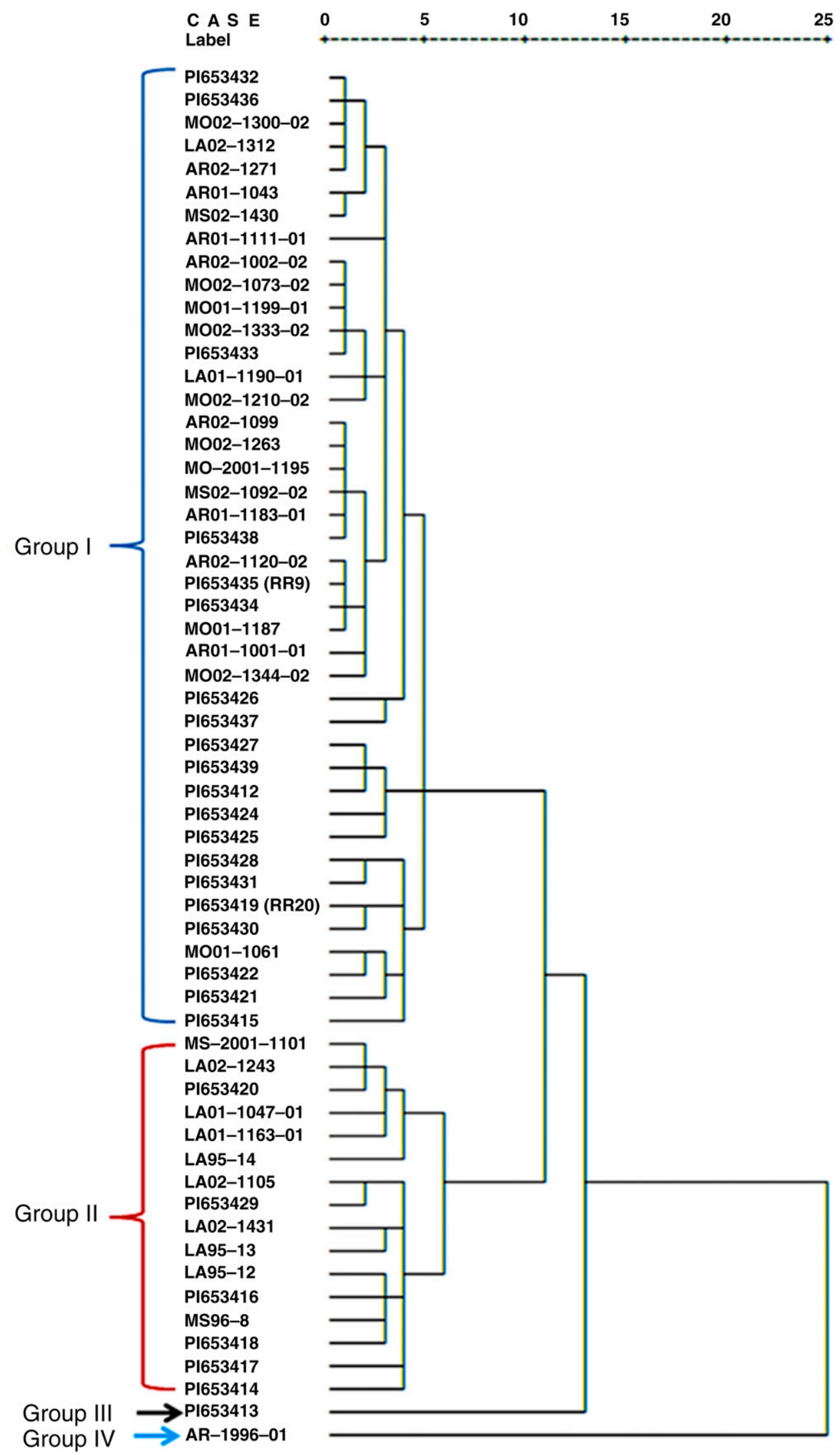

Fig. 1. Cluster analysis of 60 weedy rice accessions with rescaled distance based on the disease reactions to 14 blast races and group name shown. 
accounted for $31.32 \%$ of the disease variance in RR20. The additive effect on disease variance was $1.71 \%$ between $q B R 7.1 b$ and $q B R 12.4 b$ for race $\mathrm{IC} 1$. Using race IE $1 \mathrm{~K}$, three resistance QTL $(q B R 4.7 b, q B R 4.8 b$, and $q B R 12.5 b)$ were identified and mapped to chromosomes 4 and 12. They accounted for $20.68 \%$ of the disease variance, and the additive effect of $q B R 4.8 b$ and $q B R 12.5 b$ was $2.42 \%$. Using race IE1, two minor QTL $(q B R 4.9 b$ and $q B R 9.1 b)$ were mapped to chromosomes 4 and 9 , respectively, and one major QTL, $q B R 12.6 b$, was mapped to chromosome 12 . They accounted for $49.6 \%$ of the disease variance to race IE1 in RR20.

\section{Physical map of QTL and candidate $R$ gene prediction.}

In RR9, we identified two interesting genomic regions on chromosomes 4 and 12. One of the regions on chromosome 4 showed partial resistance to both blast races IC17 and ID1 and another one on chromosome 12 showed major resistance to both IC17 and ID1. According to the linkage and flanking markers, $q B R 4.2 s$ was mapped to the same genomic region as $q B R 4.1 \mathrm{~s}$ and had an overlap interval of $2.68 \mathrm{cM}$ on chromo-

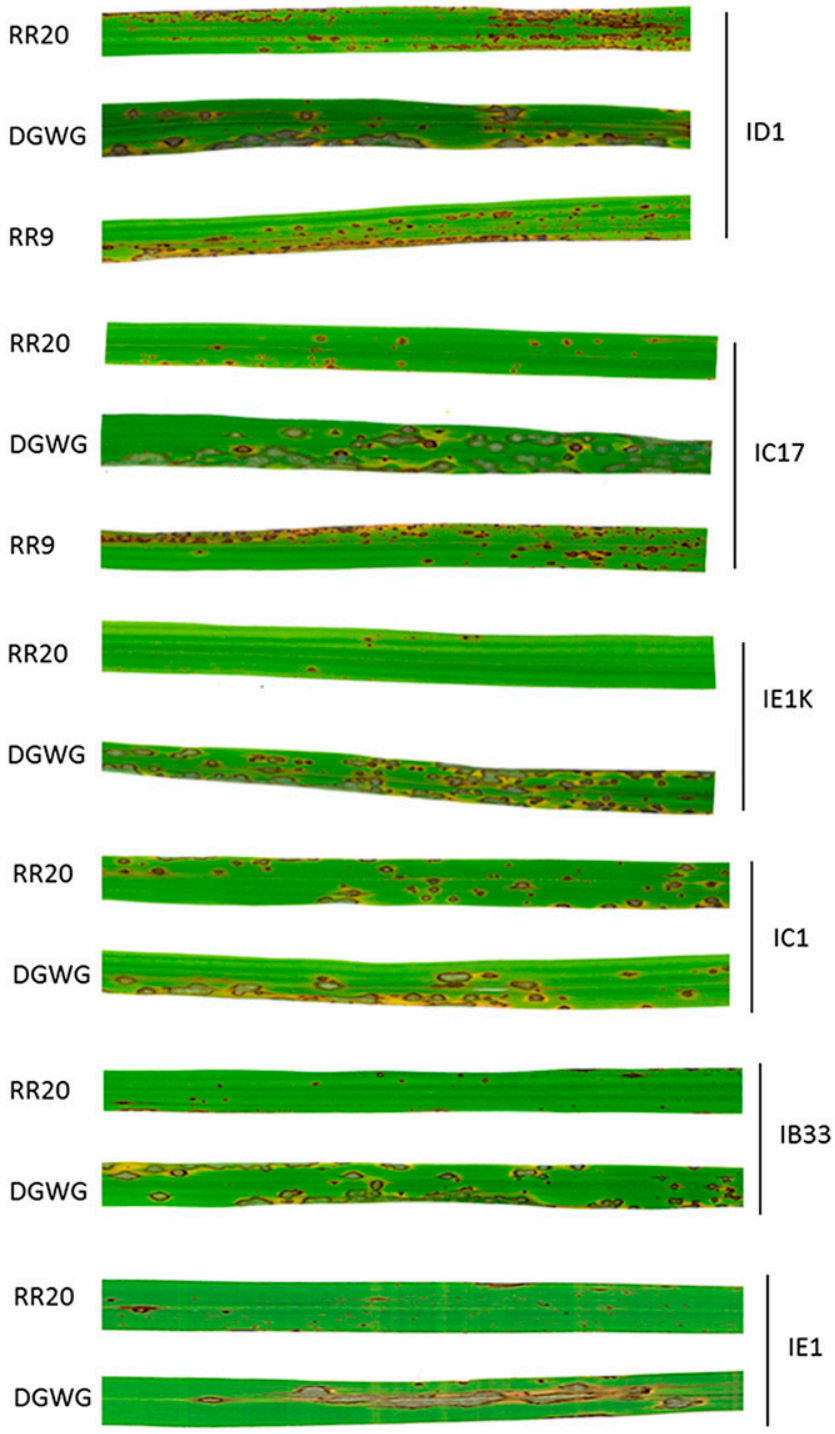

Fig. 2. Disease reactions of three parental lines to six selected blast races: ID1, IC17, IE1K, IC1, IB33, and IE1. Pictures were taken 1 week after pathogen inoculation. some 4 flanked by S4_31172494 and S4_31481685 (in Michigan State University [MSU] 6.0), which spans a 491,307-bp genomic region on chromosome 4 from $31,175,485$ to $31,666,792 \mathrm{bp}$, based on the Nipponbare reference sequence in MSU version 7.0. Two major resistance QTL, $q B R 12.1 s$ and $q B R 12.2 s$, were mapped to the same genomic region and had an overlap interval of $2.74 \mathrm{cM}$ flanked by SNP markers S_10,971,512 and S12_11,898,047 that span a 926,565-bp genomic region on chromosome 12 from $10,974,147$ to $11,900,712 \mathrm{bp}$, based on the Nipponbare reference sequence in MSU 7.0.

In RR20, we identified 22 resistance QTL using six blast races (Table 2; Fig. 4). Based on their genetic map, we found three locations on chromosomes 4 and 12 where four, five, and six QTL, respectively, were clustered. Among these, $q B R 4.1 b$, $q B R 4.4 b, q B R 4.5 b$, and $q B R 4.7 b$ were identified by the same SNP marker and mapped to the same genomic region on chromosome 4 by the same flanking SNPs S4_7805065 and S4_8208478, which spans a 403,406-bp genomic interval from $7,809,798$ to $8,213,204 \mathrm{bp}$ on chromosome 4 , based on the Nipponbare reference sequence in MSU version 7.0. Sixty-one genes were identified in this region. Of these, eight genes have putative functions and one of them was a putative $R$ gene (Table 3; Supplementary Table S4).

Out of 19 resistance QTL, $q B R 4.2 b, q B R 4.3 b, q B R 4.6 b$, $q B R 4.8 b$, and $q B R 4.9 b$ were mapped to the same location on chromosome 4 . Both QTL $q B R 4.2 b$ and $q B R 4.3 b$ were detected by the SNP marker S4_31131338. QTL $q B R 4.6 b$ and $q B R 4.8 b$ were detected by the same SNP S4_31492783. QTL $q B R 4.9 b$ was detected by SNP S4_31587811. These four QTL have an overlap flanked by SNP markers S4_31039043 and S4_31231036 which span a 301,423-bp genomic region from $31,114,715$ to $31,416,138$, based on the Nipponbare reference sequence in MSU version 7.0. Within the 301,423-bp region, 39 genes were identified. Of these, 27 genes had a putative function but there were no putative disease $R$ genes (Table 3).

In RR20, six QTL $(q B R 12.1 b, q B R 12.2 b, q B R 12.3 b$, $q B R 12.4 b, q B R 12.5 b$, and $q B R 12.6 b)$ were mapped to an approximately 3-Mb interval on chromosome 12 (Fig. 4) in which Pita and Pita-2 also are located (10,606,359 to 10,633,368 bp). Among these six resistance QTL, $q B R 12.1 b$ and $q B R 12.3 b$ differed from each other and also from Pita and Pita-2 based on their physical positions of flanking SNP markers (Table 2). $q B R 12.3 b$ was mapped to a relatively small region of $186,137 \mathrm{bp}$ from $10,636,530$ to $10,822,667 \mathrm{bp}$. Within this region, 29 genes were identified. Of these, four have a putative function but none were putative disease $R$ genes (Table 3 ). However, $q B R 12.2 b, q B R 12.4, q B R 12.5 b$, and $q B R 12.6 b$ overlapped with each other and clustered with Pita and Pita-2. Although we cannot differentiate among these four QTL based on their physical positions, they differed from Pita and Pita-2 based on their resistance spectra, in which RR20 was susceptible to race IB49, whereas varieties carrying Pita and Pita-2 were resistant to IB49.

\section{DISCUSSION}

Rice, as well as weedy rice, has been threatened by rice blast worldwide. Therefore, the studies on how weedy rice resists rice blast disease will not only provide important insights into the adaptive evolution of weedy species of rice but also may be useful in developing management strategies for blast in cultivated rice. In this study, we characterized the blast resistance traits of two weedy rice ecotypes, PI653435 (SH) and PI653419 (BHA), which present two independently evolved groups descended from closely related ancestors (Londo and Schaal 2007; Reagon et al. 2010). 
Major $R$ genes or QTL, two ways to adapt blast pathogens by U.S. weedy rice.

The investigations of the blast disease reactions of 60 weedy rice accessions suggested that U.S. weedy rice populations have adapted to blast pathogens using both major $R$ genes and QTL. We explored for evidence of the adaptive mechanisms at the molecular level by QTL mapping in two distinct U.S. weedy rice ecotypes ( $\mathrm{SH}$ and $\mathrm{BHA}$ ecotypes). Thirteen genomic loci, including 28 QTL that associated with blast resistance in two weedy rice ecotypes, were identified using advanced GBS methods and phenotypic evaluation in the greenhouse (Table 1; Fig. 4). Using GBS, several resistance QTL were mapped into relatively small genomic regions and the candidate $R$ genes were predicted.
In RR9, we identified four genomic loci, including six QTL associated with resistance to two blast races IC17 and ID1. The disease variance of these four resistance QTL ranged from 0.44 to $70.29 \%$ (Table 2), suggesting that the resistance in RR9 was controlled by one major resistance locus and three loci with relatively small effects. Analysis of the physical position of the resistance locus of $q B R 4.1 s$ and $q B R 4.2 s$ indicated that it was located at a 491,307-bp genomic region from $31,175,485$ to $31,666,792 \mathrm{bp}$ on chromosome 4 , which contributed partial resistance to both blast races IC17 and ID1. The locus of $q B R 12.1 s$ and $q B R 12.2 s$ was located at a 926,565-bp genomic region from $10,974,147$ to $11,900,712$ bp on chromosome 12 , which showed major resistance to both IC17 and ID1. Moreover, both of these loci on chromosome 4 and 12 were also
A

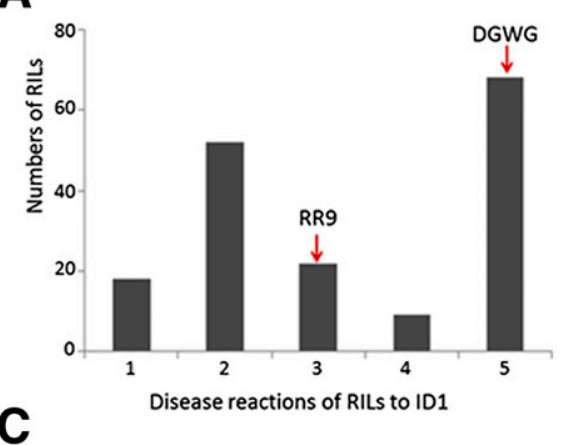

C

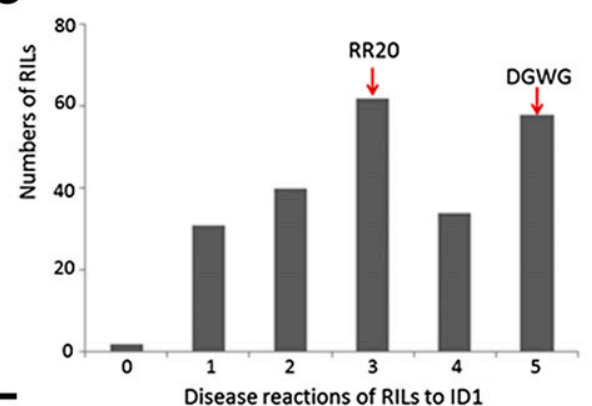

E

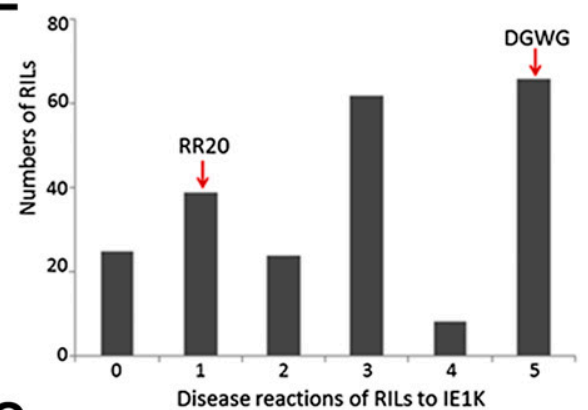

G

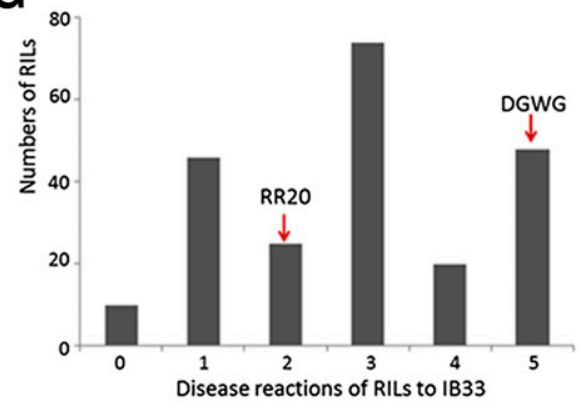

B
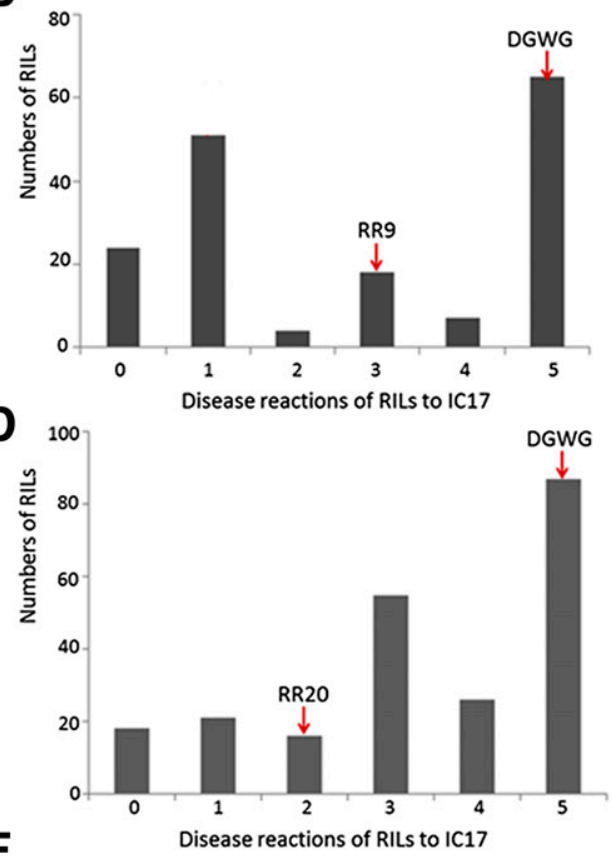

$\mathbf{F}$

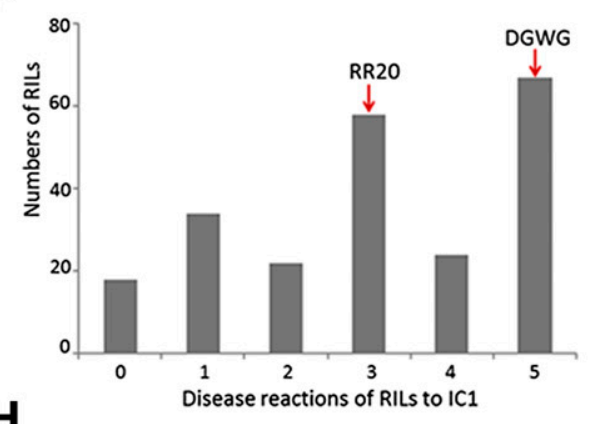

$\mathbf{H}$

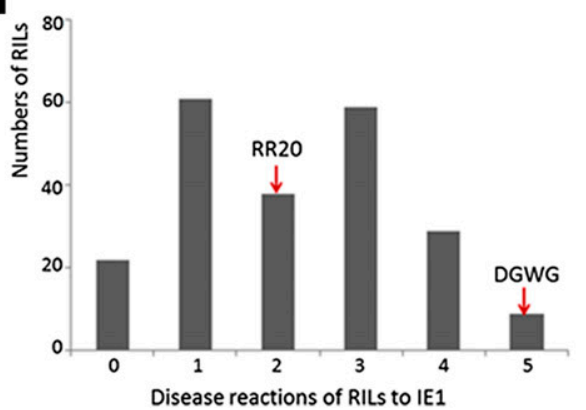

Fig. 3. Distribution of blast disease reactions of two $\mathrm{F}_{8}$ recombinant inbred line populations to tested blast races. Parental lines were indicated in each graph. A and $\mathbf{B}$, Phenotypic distribution of disease reactions of the $\mathrm{S}$ population; $\mathbf{C}$ to $\mathbf{H}$, phenotypic distribution of disease reaction of the $\mathrm{B}$ population. 
identified in black hull weedy rice RR20 using races IC17, ID1, IC1, IE1K, and IE1, and they may share the same $R$ genes.

In RR20, we identified nine genomic loci, including 22 resistance QTL, with a disease variance ranging from 1.08 to $37.97 \%$. Among the 18 resistance QTL, 15 showed relatively small disease effects ranging from 1.08 to $13.57 \%$, and 3 resistance QTL $(q B R 4.3 b, q B R 12.2 b$, and $q B R 12.6 b)$ showed disease effects of $24.68,25.58$, and $37.97 \%$, respectively. The resistance to each race was controlled by two to seven genomic loci with small effects. Out of nine genomic loci, we found three loci clustered by 15 resistance QTL on chromosomes 4 and 12 (Fig. 4). Of these three loci, one clustered by four resistance QTL was located at a 403,406-bp genomic interval from $7,809,798$ to $8,213,204$ bp on chromosome 4, where no known $R$ genes are present. The second loci clustered by five resistance QTL was located at a 301,423-bp genomic region from $31,114,715$ to $31,416,138$ bp on chromosome 4 , which is close to but different from Pi63, the newly cloned blast $R$ gene located in the genome region from $31,267,316$ to $31,559,326 \mathrm{bp}$ (Xu et al. 2014). The third locus, clustered near six resistance QTL, was located in a genome interval of approximately $3 \mathrm{Mb}$ on chromosome 12 (Fig. 4), where Pita and Pita-2 were located $(10,606,359$ to $10,633,368 \mathrm{bp})$. This resistance locus on chromosome 12 could not be differentiated from the known $R$ genes based on their physical position. However, the resistance locus on chromosome 12 did exhibit a different resistance spectrum which differed from that of Pita and Pita-2. RR20 was resistant to the blast races IB33, IE1K, and IC1 and susceptible to race IB49, whereas the 'Katy', which contains Pita and Pita-2, was susceptible to IB33, IE1K, and IC1 and resistant to IB49. Therefore, we conclude that the $R$ genes under this locus are different from the known $R$ genes Pita and Pita-2.

Of 28 resistance QTL, 5 QTL $(q B R 12.1 s, q B R 12.2 s$, $q B R 4.3 b, q B R 12.2 b$, and $q B R 12.6$ ) had a relatively large effect on disease variance (Table $2 ; R^{2}$ of 24.68 to $70.29 \%$ ). Twentythree QTL had a relatively small effect on the disease variance.

Although the two populations have a relatively small number of RILs which limit the genomic size of the identified QTL, we were able to map three resistance QTL into relatively fine regions using GBS methods. Analysis of the candidate genes within the three fine-resistance QTL regions (Table 3) found no classical disease resistance nucleotide-binding site leucine-rich repeat protein but did identify one putative RPM1 protein, which controls the extent of cell death and overall resistance response at the site of infection with the onset of the hypersensitive response (Boyes et al. 1998). This result also suggests that novel $R$ genes may control the resistance in weedy rice RR9 and RR20.

The utilization of major $R$ genes to adapt pathogens in plants has been challenged by variable pathogen populations because

Table 2. Blast disease resistance quantitative trait loci (QTL) identified in this study

\begin{tabular}{|c|c|c|c|c|c|c|c|c|}
\hline Race, QTL $^{\mathbf{a}}$ & Chr $^{\mathbf{b}}$ & Nearest marker & \multicolumn{2}{|c|}{ Flanking markers (MSU6) } & $\mathrm{R2}(\%)^{\mathrm{c}}$ & $\operatorname{LOD}^{\mathrm{d}}$ & Interval $(\mathbf{c M})^{\mathrm{e}}$ & Additive effects $R^{2}(\%)$ \\
\hline \multicolumn{9}{|l|}{ S population } \\
\hline \multicolumn{9}{|l|}{ IC17 } \\
\hline$q B R 4.1 \mathrm{~s}$ & 4 & S4_31225606 & S4_30698436 & S4_31814985 & $0.44 *$ & 3.90 & 9.12 & No \\
\hline$q B R 5.1 \mathrm{~s}$ & 5 & S5_258527 & S5_202353 & S5_658958 & $0.72 *$ & 4.20 & 3.43 & No \\
\hline$q B R 12.1 \mathrm{~s}$ & 12 & $\mathrm{~S} 1 \overline{2} \_11312938$ & $\mathrm{~S} 1 \overline{2} \_10971512$ & S12_11898047 & $70.29 * * *$ & 52.89 & 2.74 & No \\
\hline \multicolumn{9}{|l|}{ ID1 } \\
\hline$q B R 4.2 s$ & 4 & S4_31393209 & S4_31172494 & S4_3148168 & $5.6 * * *$ & 7.54 & 2.68 & No \\
\hline$q B R 11.1 \mathrm{~s}$ & 11 & S11_25150111 & S11__24626400 & S11_26217685 & $2.17 * * *$ & 3.59 & 6.3 & No \\
\hline$q B R 12.2 s$ & 12 & S12_11312938 & S12_10971512 & S12_12130319 & $68.04 * * *$ & 46.16 & 3.09 & No \\
\hline \multicolumn{9}{|l|}{ B population } \\
\hline \multicolumn{9}{|l|}{ IC17 } \\
\hline$q B R 4.1 b$ & 4 & S4_8039007 & S4_7805065 & S4_8208478 & $4.85^{* * *}$ & 18.52 & 0.39 & $\ldots$ \\
\hline$q B R 4.2 b$ & 4 & S4_31131338 & S4_31039043 & S4_31846929 & $13.57 * * *$ & 9.55 & 5.75 & \\
\hline$q B R 12.1 b$ & 12 & $\mathrm{~S} 1 \overline{2} \_10182426$ & $\mathrm{~S} 1 \overline{2} \_7933473$ & $\mathrm{~S} 1 \overline{2} \_10283974$ & $2.71 * *$ & 20.98 & 1.93 & $1.96 * *(q B R 4.2 b * q B R 12.1 b)$ \\
\hline \multicolumn{9}{|l|}{ ID1 } \\
\hline$q B R 4.3 b$ & 4 & S4_31131338 & S4_30889926 & S4_31231036 & $24.68 * * *$ & 14.19 & 0.26 & No \\
\hline$q B R 12.2 b$ & 12 & S12__10137687 & S12_9862443 & S12_13450846 & $25.58 * * *$ & 14.73 & 2.49 & No \\
\hline \multicolumn{9}{|l|}{ IB33 } \\
\hline$q B R 1.1 b$ & 1 & $\mathrm{~S} 1 \_39636658$ & S1_35457400 & S1_38572651 & $2.90 * * *$ & 8.35 & 10.14 & No \\
\hline$q B R 4.4 b$ & 4 & S4_8039007 & S4_7805065 & S4_8208478 & $1.37 * *$ & 32.05 & 0.39 & No \\
\hline$q B R 11.1 \mathrm{~b}$ & 11 & S11_3728585 & S11_3718727 & S11_6922622 & $1.08 *$ & 3.95 & 15.33 & No \\
\hline$q B R 12.3 b$ & 12 & S12_1072443 & S12_10633942 & S12_10820033 & $7.50 * * *$ & 37.24 & 0.35 & No \\
\hline \multicolumn{9}{|l|}{ IC 1} \\
\hline$q B R 1.2 b$ & 1 & S1_9872665 & S1_8900503 & S1_11455784 & $2.89^{* * *}$ & 3.98 & 15.40 & \\
\hline$q B R 2.1 b$ & 2 & S2_8702061 & S2_8583784 & S2_8746579 & $1.22 *$ & 5.96 & 1.18 & $\ldots$ \\
\hline$q B R 4.5 b$ & 4 & S4_8039007 & S4_7805065 & S4_8208478 & $7.96 * * *$ & 15.66 & 0.39 & $\ldots$ \\
\hline$q B R 4.6 b$ & 4 & S4_31492783 & S4_30889926 & S4_31773254 & $10.71 * * *$ & 8.17 & 5.93 & $\ldots$ \\
\hline$q B R 7.1 b$ & 7 & S7_16453698 & S7_7662026 & S7_22294235 & $4.32 * * *$ & 5.14 & 37.11 & $\ldots$ \\
\hline$q B R 11.2 b$ & 11 & S11_2914150 & S11_2353763 & S11_3903404 & $2.23 * *$ & 3.99 & 8.40 & $\ldots$ \\
\hline$q B R 12.4 b$ & 12 & S12_10633942 & S12_9862443 & S12_14046403 & $1.99 *$ & 18.9 & 3.47 & $1.71 * *(q B R 7.1 b * q B R 12.4 b)$ \\
\hline \multicolumn{9}{|r|}{ 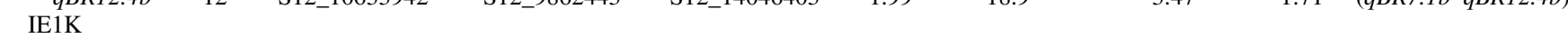 } \\
\hline$q B R 4.7 b$ & 4 & S4_8039007 & S4_7805065 & S4_8208478 & $4.99 * * *$ & 15.98 & 0.39 & $\ldots$ \\
\hline$q B R 4.8 b$ & 4 & S4_31492783 & S4_31039043 & S4_31777369 & $12.14 * * *$ & 18.26 & 5.31 & \\
\hline \multirow{2}{*}{\multicolumn{9}{|c|}{2.42 (qDN 4.00 QDNIL }} \\
\hline & & & & & & & & \\
\hline$q B R 4.9 b$ & 4 & S4_31587811 & S4_30880513 & S4_33044513 & $3.69 * * *$ & 3.269 & 10.30 & No \\
\hline$q B R 9.1 b$ & 9 & S9_20976650 & S9_20794074 & S9_21001595 & $7.98 * * *$ & 7.083 & 1.23 & No \\
\hline$q B R 12.6 b$ & 12 & S12_10668728 & S12_10137687 & S12_10768120 & $37.97 * * *$ & 24.27 & 1.03 & No \\
\hline
\end{tabular}


of the race specificity. However, combining major $R$ genes and minor resistance QTL in the elite rice varieties is thought to be more durable and adaptive. Results from this research suggest that the resistance in U.S. weedy rice was controlled by major $R$ genes or minor resistance (QTL) and some of them were norace specific, which may facilitate the adaptation of U.S. weedy rice to rice blast pathogens.

\section{Convergent blast resistance phenotype controlled by same or different genes.}

Convergent phenotypic evolution is believed to be one of the common phenomena for weedy rice populations to adapt to local environments. U.S. weedy rice groups have evolved several convergent weed-adaptive traits such as rapid growth, increased seed shattering, and dormancy to facilitate successful invasion of rice fields, providing an ideal system for the study of the convergent evolution. Recently, studies on the identification of QTL associated with weedy traits in U.S. weedy rice found that similar traits such as seed shattering were controlled by different genes but divergent phenotypic traits may share the same genes (Thurber et al. 2013).

Twenty-eight resistance QTL, which are associated with different rice blast disease resistance in two genetically distinct weedy rice ecotypes, were identified in the present study. Both RR9 and RR20 ecotypes exhibited resistance to blast races IC17 and ID1. However, we identified six resistance QTL in RR9 using the $S$ population and found five resistance QTL in RR20 using the B population. Among the $11 \mathrm{QTL}, q B R 4.1 s, q B R 4.2 s$, $q B R 4.2 b$, and $q B R 4.3 b$ were mapped to the same genomic region on chromosome 4 , which may be controlled by the same $R$ genes. $q B R 12.1 s, q B R 12.2 s, q B R 12.1 b$, and $q B R 12.2 b$ were mapped to the same region or a cluster on chromosome 12, which may be controlled by the same $R$ genes. This result supports the hypothesis that some of the convergent phenotype traits may be controlled by the same genes. Of 11 QTL, there are 3 minor QTL $(q B R 5.1 s, q B R 11.1 s$, and $q B R 4.1 b)$ that were different from each other in RR9 and RR20, and that were mapped to different chromosomes (Table 2; Fig. 4). This result implies that different weedy rice ecotypes may use different genetic mechanisms to respond to rice blast pathogens.

\section{A potential source of novel blast $\boldsymbol{R}$ genes for resistance breeding.}

The selective forces imposed by novel environments may result in the diversification of adaptive strategy of weed rice populations. Recently, the genetic diversity of genes underlying several important weedy traits and agricultural traits were investigated in U.S. weedy rice (Craig et al. 2014; Gross et al. 2009, 2010; Reagon et al. 2011; Thurber et al. 2010). U.S. weedy rice exhibits a very wide range of phenotypic and complex genetic diversity, which may have facilitated its successful invasion into novel environments by adaption (Gealy et al. 2002; 2012; Olsen et al. 2007; Reagon et al. 2010; Shivrain et al. 2010a,b). The disease reactions of 60 U.S. weedy rice ecotypes suggested that U.S. weedy rice ecotypes exhibited a broad range of disease resistance to blast pathogen. The 60 weedy rice ecotypes were
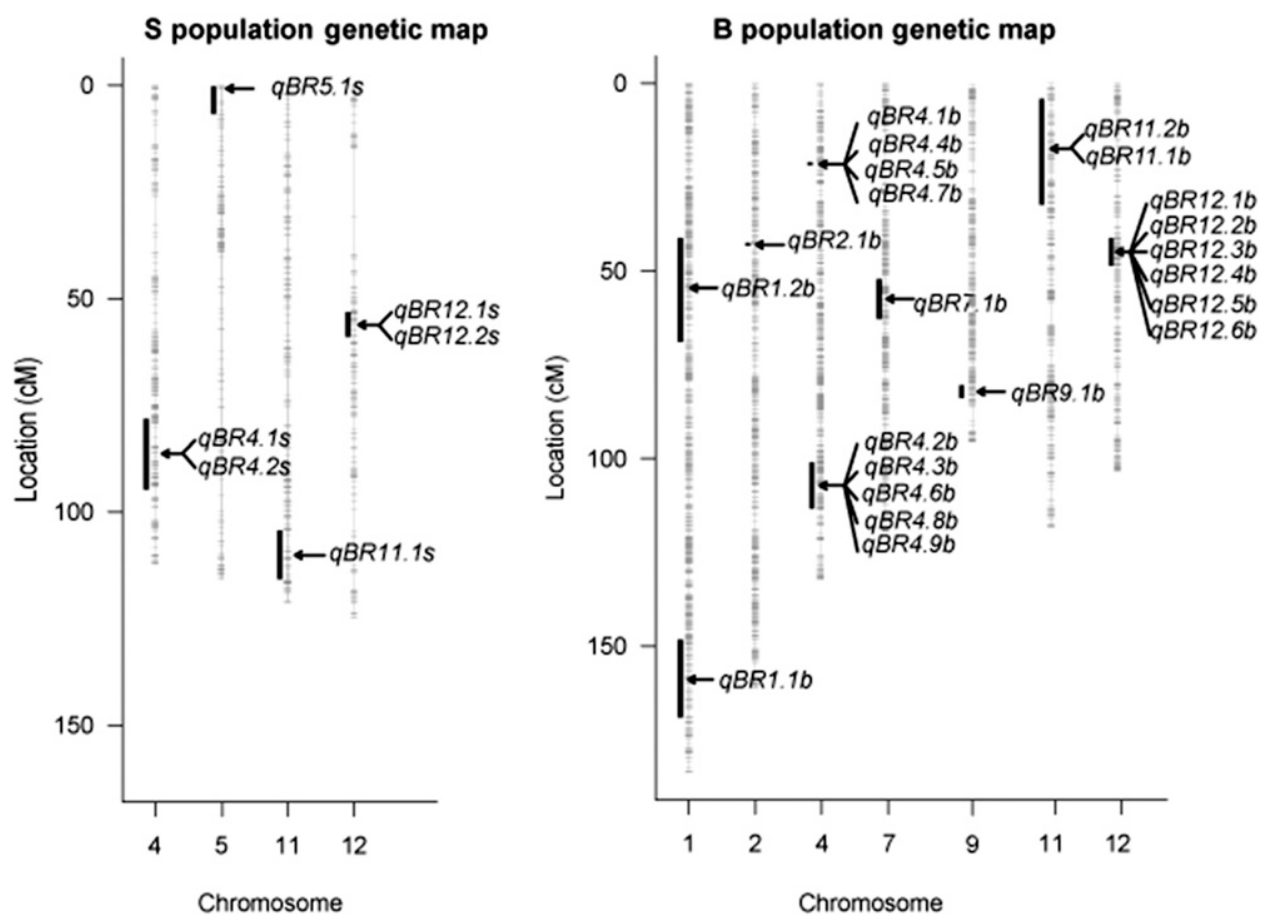

Fig. 4. High-resolution genetic map with the positions of six resistance quantitative trait loci (QTL) detected in U.S. weedy rice RR9 and 22 resistance QTL detected in U.S. weedy rice RR20. Positions of the resistance QTL are indicated using black arrows. Black bars on the left side of the each chromosome represent the length of QTL.

Table 3. Numbers of putative candidate resistance $(R)$ genes within three regions on chromosomes 4 and 12

\begin{tabular}{lcccc}
\hline Genomic loci of quantitative trait loci & Physical distance (bp) & Number of putative genes & Number of candidate genes & Putative disease $\boldsymbol{R}$ genes $^{\mathbf{a}}$ \\
\hline Cluster of $q B R 4.1 b$ & 403,406 & 61 & 8 & One RPM1 protein \\
Cluster of $q B R 4.2 b$ & 301,423 & 39 & 27 & None \\
$q B R 12.3 b$ & 186,137 & 29 & 4 & None \\
\hline
\end{tabular}

\footnotetext{
${ }^{a}$ RPM1 protein is a putative disease $\mathrm{R}$ protein.
} 
placed into four groups using cluster analysis of the disease reactions. Weedy rice in different groups exhibited different resistance spectra to rice blast races. The weedy rice ecotypes in groups II, III, and IV exhibited a broad-spectrum resistance (Table 1; Fig. 1). The results indicated that weedy rice responds and adapts to blast disease in a variety of ways.

Transferring disease $R$ genes from resistant germplasm into cultivated rice has been an effective way to breed new diseaseresistant varieties. However, $R$ genes flowing from crop to weed may create new problems. Several studies have suggested that crop-weed outcrossing is an important contributor to gene flow between rice and weedy rice (Burgos et al. 2014; Messeguer et al. 2004; Shivrain et al. 2007; Zhang et al. 2006). Transferring of herbicide resistance to weeds from genetically altered crops is a good example of gene flow through crop-weed hybridization (Chen et al. 2004; Snow et al. 1999; Song et al. 2009). In the present study, we found that most of the resistance in weedy rice belongs to partial resistance instead of complete resistance. However, the weed-crop hybrid ecotype AR-199601 exhibited a complete disease resistance to 10 blast races, which implied that some of these complete $R$ genes might be transferred from cultivated rice to weedy rice through the hybridization between weed and crop. Further study is needed to explore this hypothesis in the future.

\section{Summary.}

This is the first report to investigate QTL with resistance to rice blast in U.S. weedy rice. These findings not only provided important insights into the molecular basis of adaptive evolution but also discovered a potentially important resistance resource for U.S. rice breeders. Five loci with broad resistance spectra defined in weedy rice can be used to breed for durable resistance to blast pathogens. Future research will focus on fine mapping and validation of three genomic regions to determine the extent of the contributions of the candidate genes for each QTL.

\section{MATERIALS AND METHODS}

\section{Plant materials.}

In total, 60 U.S. weedy rice accessions, including four different groups-SH, BHA, brown hull (BR), and crop-weed hybrids (MIX) (Gealy et al. 2002)—were collected from 1994 to 2004 from rice fields in the southern United States. These ecotypes were subsequently grown for seed increase in research fields at the United States Department of AgricultureAgricultural Research Service, Dale Bumpers National Rice Research Center (USDA-ARS DB NRRC) in Stuttgart, AR using single-seed descent. The SH and BHA ecotypes were the most common weedy rice ecotypes and the BR ecotype is believed to be the progeny of crosses between SH and BHA ecotypes (Reagon et al. 2010). Two RIL populations were used for blast disease resistance QTL mapping. One RIL population, designated as the $\mathrm{S}$ population, included 175 individuals that were derived from the cross of DGWG and the straw hull weedy rice type PI653435 (AR-2001-1135; RR9; S population). The other population, designated as the B population, included 224 individuals that were derived from the cross of DGWG and a black hull type PI653419 (MS-1996-9; RR20; B population). The two weedy rice parents, RR9 and RR20, are representative of the SH and BHA populations, respectively, of U.S. weedy rice (Reagon et al. 2010; Thurber et al. 2013). The indica rice was chosen as a parent because indica rice is the putative ancestor of the $\mathrm{SH}$ weedy rice and is closely related to the BHA ancestor, aus (Thurber et al. 2013). Moreover, the indica variety DGWG is a known variety which is the source of the semidwarf gene $(S D 1)$ and played an important role in the
Green Revolution. Weed and crop parents were selected to maximize the phenotypic differences in potential weed-adaptive traits, such as shattering, dormancy, awns, heading date, plant height growth rate, and disease resistance. $\mathrm{F}_{5}$ RILs of the two mapping populations, including 175 individuals from the $\mathrm{S}$ population and 224 individuals from the $\mathrm{B}$ population, were used for GBS. $F_{6}$ and $F_{7}$ RILs, including 175 individuals from the $\mathrm{S}$ population and 224 individuals from the $\mathrm{B}$ population, were grown in the field in summer 2012 at USDA-ARS, DB NRRC to increase seeds. Two $\mathrm{F}_{8}$ RIL populations, 175 individuals from the $S$ population and 224 individuals from the $B$ population, were used for disease evaluation in a greenhouse at USDA-ARS, DB NRRC.

\section{Evaluation of blast disease reaction.}

Seeds of weedy rice and RILs were randomly grown in plastic trays ( 54 by 28 by $6 \mathrm{~cm}$ ), with three replicates of 10 plants per line in the greenhouse. Seedlings were grown under greenhouse conditions at a temperature of 25 to $30^{\circ} \mathrm{C}$. In total, 14 blast races, including 13 common rice blast races collected from U.S. rice fields-IC1 (BRFD-2F-2), IC17 (ZN57), IE1K (TM2), ID1 (ZN42), IB54 (isolate unnamed), IB49 (ZN61), IB1 (isolate unnamed), IA1 (BRFD-21-2), IG1 (ZN39), IE1 (ZN13), IB45 (isolate unnamed), IA45(75L14), and IH1 (isolate unnamed) - and 1 lab race IB33 (FL9), were used for disease evaluation of weedy rice in the greenhouse. Based on the disease reactions of three parental lines to 14 blast races, IC17 and ID1 were selected and used for disease evaluation of individuals of the S population; and IC17, ID1, IE1K, IC1, and IB33 were selected and used for disease evaluation of the B population. Blast isolates (Table 2) were prepared following the procedure described by Jia and Liu (2011). Inoculation and disease assays were modified based on the method described by Liu et al. (2015). The concentration of spore suspension was adjusted to approximately $1 \times 10^{5}$ spores $/ \mathrm{mL}$ in $0.25 \%$ gelatin solution. The 21-day-old rice seedlings (three- to four-leaf stage) were sprayed with $30 \mathrm{~mL}$ of spore suspension per tray in a black plastic bag. The inoculated seedlings were sealed in the inoculated bags and maintained at a temperature of $25^{\circ} \mathrm{C}$ and high humidity condition ( $>90 \%$ relative humidity) for $24 \mathrm{~h}$, then transferred to the greenhouse at 25 to $28^{\circ} \mathrm{C}$, with 60 to $90 \%$ relative humidity and $12 \mathrm{~h}$ each of daylight and darkness. Disease reactions were determined at 7 days after inoculation using a scale of 0 to 5 , where 0 was considered complete resistance, 1 and 2 were partial resistance, 3 was partially susceptible, and 4 to 5 were susceptible. Disease reaction scores were determined on all 10 plants per line.

\section{Genotyping analysis.}

All the individuals of two $F_{5}$ RIL populations and their parental lines were genotyped using GBS. Plant genomic DNA from the leaves of 175 and $224 \mathrm{~F}_{5}$ RILs were extracted using QIAamp DNA Mini Kit following the manufacturer's protocol (Qiagen, Maryland, U.S.A.). Genomic DNAs were digested using restriction enzyme ApeKI and bar coded following the protocol as described by (Elshire et al. 2011). Sets of 96 samples per lane were sequenced with an Illumina HiSeq DNA sequencer at Cornell University's Institute for Genomic Diversity (Ithaca, NY, U.S.A.) using their standard protocol. The raw data were processed using the standard Tassel GBS pipeline (Glaubitz et al. 2014). SNP calls were made based on the Nipponbare reference genome sequences, built on MSU 6.0 (available online at ftp://ftp.plantbiology.msu.edu/pub/data/ Eukaryotic_Projects/o_sativa/annotation_dbs/pseudomolecules/ version_6.0/) using the Burrows-Wheeler alignment tool ( $\mathrm{Li}$ and Durbin 2009). SNPs with $>10 \%$ missing data, individuals with $>95 \%$ missing data, and monomorphic SNPs with missing 
data were all removed before further analysis. After filtering, 12 and 1 individuals were removed from the S and B populations, respectively, and 167,464 and 175,333 SNPs were removed from these two populations, respectively. The genotypic data of two populations are available for download from the Dryad repository.

\section{QTL mapping.}

A high-resolution genetic linkage map was generated using the R/qtl software package (Broman and Sen 2009). Genetic positions of the SNPs were identified using cM Converter based on the physical positions of SNPs on the MSU 6.0 genome annotation. For each set of phenotypic data, QTL were analyzed using both single-marker analysis and composite interval mapping methods of the R/qtl package, and both Haley-Knott regression and multiple imputation (Haley and Knott 1992) programs, respectively, were used for data analysis (Sen and Churchill, 2001). A permutation test was carried out for each dataset $(n=1,000)$ to obtain a genome-wide significance threshold. The 1.5 LOD confidence interval of each detected QTL was calculated using the lodint function. The find.marker function was used to select the nearest marker of each QTL. The additive effect was estimated to assess the possibility of an interaction between any pairs of QTL using the addint function.

\section{Prediction of candidate $R$ genes.}

To predict the candidate $R$ genes, the physical positions of SNPs flanking the target QTL regions were converted from MSU 6.0 to the most recent MSU 7.0 genome annotation. The QTL intervals were delimited by the flanking SNP markers. Candidate $R$ genes were predicted within the fine-mapped QTL regions based on the output of gene prediction by the Rice Genome Annotation Project-MSU Rice Genome Annotation (Osa1) Release 7 (http:// rice.plantbiology.msu.edu/cgi-bin/gbrowse/rice/).

\section{ACKNOWLEDGMENTS}

We thank M. A. Nohatto, C. Torrence, M. Lin, H. Black, and T. Bianco for their excellent technical support. This project was funded, in part, by the National Science Foundation Plant Genome Research Program (NSF award IOS-1032023). The United States Department of Agriculture is an equal opportunity provider and employer.

\section{LITERATURE CITED}

Ågren, J., Oakley, C. G., McKay, J. K., Lovell, J. T., and Schemske, D. W. 2013. Genetic mapping of adaptation reveals fitness tradeoffs in Arabidopsis thaliana. Proc. Natl. Acad. Sci. U.S.A. 110:21077-21082.

Anderson, J. T., Lee, C. R., Rushworth, C. A., Colautti, R. I., and MitchellOlds, T. 2013. Genetic trade-offs and conditional neutrality contribute to local adaptation. Mol. Ecol. 22:699-708.

Anderson, J. T., Willis, J. H., and Mitchell-Olds, T. 2011. Evolutionary genetics of plant adaptation. Trends Genet. 27:258-266.

Ballini, E., Morel, J. B., Droc, G., Price, A., Courtois, B., Notteghem, J. L., and Tharreau, D. 2008. A genome-wide meta-analysis of rice blast resistance genes and quantitative trait loci provides new insights into partial and complete resistance. Mol. Plant-Microbe Interact. 21:859-868.

Boyes, D. C., Nam, J., and Dangl, J. L. 1998. The Arabidopsis thaliana RPM1 disease resistance gene product is a peripheral plasma membrane protein that is degraded coincident with the hypersensitive response. Proc. Natl. Acad. Sci. U.S.A. 95:15849-15854.

Broman, K. W., and Sen, S. 2009. A Guide to QTL Mapping with R/qtl. Springer, New York.

Burgos, N. R., Singh, V., Tseng, T. M., Black, H. L., Young, N. D., Huang, Z., Hyma, K. E., Gealy, D. R., and Caicedo, A. L. 2014. The impact of herbicide-resistant rice (Oryza sativa L.) technology on phenotypic diversity and population structure of United States weedy rice. Plant Physiol. 166:1208-1220.

Chen, L. J., Lee, D. S., Song, Z. P., Suh, H. S., and Lu, B. R. 2004. Gene flow from cultivated rice (Oryza sativa) to its weedy and wild relatives. Ann. Bot. (Lond.) 93:67-73.
Craig, S. M., Reagon, M., Resnick, L. E., and Caicedo, A. L. 2014. Allele distributions at hybrid incompatibility loci facilitate the potential for gene flow between cultivated and weedy rice in the US. PLoS One 9: e86647.

Daub, J. T., Hofer, T., Cutivet, E., Dupanloup, I., Quintana-Murci, L., Robinson-Rechavi, M., and Excoffier, L. 2013. Evidence for polygenic adaptation to pathogens in the human genome. Mol. Biol. Evol. 30: 1544-1558.

Delouche, J. C., Burgos, N. R., Gealy, D. R., Zorrilla de San Martin, G., and Labrada, R. 2007. Weedy Rices: Origin, Biology, Ecology and Control. Food and Agriculture Organization (FAO) of the United Nations, Rome.

Dittmar, E. L., Oakley, C. G., Ågren, J., and Schemske, D. W. 2014. Flowering time QTL in natural populations of Arabidopsis thaliana and implications for their adaptive value. Mol. Ecol. 23:4291-4303.

Elshire, R. J., Glaubitz, J. C., Sun, Q., Poland, J. A., Kawamoto, K. Buckler, E. S., and Mitchell, S. E. 2011. A robust, simple genotyping-bysequencing (GBS) approach for high diversity species. PLoS One 6: e19379.

Estorninos, L. E., Jr., Gealy, D. R., Gbur, E. E., Talbert, R. E., and McClelland, M. R. 2005. Rice and red rice interference. II. Rice response to population densities of three red rice (Oryza sativa) ecotypes. Weed Sci. 53:683-689.

Gealy, D. R., Agrama, H. A., and Jia, M. H. 2012. Genetic analysis of atypical U.S. red rice phenotypes: Indications of prior gene flow in rice fields? Weed Sci. 60:451-461.

Gealy, D. R., Tai, T. H., and Sneller, C. H. 2002. Identification of red rice, rice, and hybrid populations using microsatellite markers. Weed Sci. 50: 333-339.

Glaubitz, J. C., Casstevens, T. M., Lu, F., Harriman, J., Elshire, R. J., Sun, Q., and Buckler, E. S. 2014. TASSEL-GBS: A high capacity genotyping by sequencing analysis pipeline. PLoS One 9:e90346.

Gross, B. L., Reagon, M., Hsu, S. C., Caicedo, A. L., Jia, Y., and Olsen, K. M. 2010. Seeing red: The origin of grain pigmentation in US weedy rice. Mol. Ecol. 19:3380-3393.

Haley, C. S., and Knott, S. A. 1992. A simple regression method for mapping quantitative trait loci in line crosses using flanking markers. Heredity 69:315-324

Gross, B. L., Skare, K. J., and Olsen, K. M. 2009. Novel Phrl mutations and the evolution of phenol reaction variation in US weedy rice (Oryza sativa). New Phytol. 184:842-850.

Jia, Y., and Liu, G. 2011. Mapping quantitative trait loci for resistance to rice blast. Phytopathology 101:176-181.

Lee, S., Jia, Y., Jia, M., Gealy, D. R., Olsen, K. M., and Caicedo, A. L. 2011 Molecular evolution of the rice blast resistance gene Pi-ta in invasive weedy rice in the USA. PLoS One 6:e26260.

Lee, S., Wamishe, Y., Jia, Y., Liu, G., and Jia, M. H. 2009. Identification of two major resistance genes against race IE-1k of Magnaporthe oryzae in the indica rice cultivar Zhe733. Mol. Breed. 24:127-134.

Li, H., and Durbin, R. 2009. Fast and accurate short read alignment with Burrows-Wheeler transform. Bioinformatics 25:1754-1760.

Liu, Y., Liu, B., Zhu, X., Yang, J., Bordeos, A., Wang, G., Leach, J. E., and Leung, H. 2013. Fine-mapping and molecular marker development for Pi56(t), a NBS-LRR gene conferring broad-spectrum resistance to Magnaporthe oryzae in rice. Theor. Appl. Genet. 126:985-998.

Liu, Y., Qi, X., Young, N. D., Olsen, K. M., Caicedo, A. L., and Jia, Y. 2015. Characterization of resistance genes to rice blast fungus Magnaporthe oryzae in a "Green Revolution" rice variety. Mol. Breed. 35:52.

Londo, J. P., and Schaal, B. A. 2007. Origins and population genetics of weedy red rice in the USA. Mol. Ecol. 16:4523-4535.

Messeguer, J., Marfa, V., Catala, M. M., Guiderdoni, E., and Mele, E. 2004 A field study of pollen-mediated gene flow from Mediterranean GM rice to conventional rice and the red rice weed. Mol. Breed. 13:103-112.

Oakley, C. G., Ågren, J., Atchison, R. A., and Schemske, D. W. 2014. QTL mapping of freezing tolerance: Links to fitness and adaptive trade-offs. Mol. Ecol. 23:4304-4315.

Olsen, K. M., Caicedo, A. L., and Jia, Y. 2007. Evolutionary genomics of weedy rice in the USA. J. Integr. Plant Biol. 49:811-816.

Pritchard, J. K., and Di Rienzo, A. 2010. Adaptation-Not by sweeps alone. Nat. Rev. Genet. 11:665-667.

Reagon, M., Thurber, C. S., Gross, B. L., Olsen, K. M., Jia, Y., and Caicedo, A. L. 2010. Genomic patterns of nucleotide diversity in divergent populations of U.S. weedy rice. BMC Evol. Biol. 10:180.

Reagon, M., Thurber, C. S., Olsen, K. M., Jia, Y., and Caicedo, A. L. 2011. The long and the short of it: SD1 polymorphism and the evolution of growth trait divergence in U.S. weedy rice. Mol. Ecol. 20:3743-3756.

Scheinfeldt, L. B., and Tishkoff, S. A. 2013. Recent human adaptation: Genomic approaches, interpretation and insights. Nat. Rev. Genet. 14: 692-702. 
Sen, S., and Churchill, G. A. 2001. A statistical framework for quantitative trait mapping. Genetics 159:371-387.

Sharma, T. R., Rai, A. K., Gupta, S. K., Vijayan, J., Devanna, B. N., and Ray, S. 2012. Rice blast management through host-plant resistance: Retrospect and prospects. Agric. Res. 1:37-52.

Shivrain, V. K., Burgos, N. R., Agrama, H. A., Lawton-Rauh, A., Lu, B., Sales, M. A., Boyett, V., Gealy, D. R., and Moldenhauer, K. A. K. 2010a. Genetic diversity of weedy rice (Oryza sativa) in Arkansas, USA. Weed Res. 50:289-302.

Shivrain, V. K., Burgos, N. R., Rajguru, S. N., Sales, M. A., and Smith, K. L. 2007. Gene flow between Clearfield ${ }^{\mathrm{TM}}$ rice and red rice. Crop Prot. 26:349-356.

Shivrain, V. K., Burgos, N. R., Scott, R. C., Gbur, E. E., Jr., Estorninos, L. E., Jr., and McClelland, M. R. 2010b. Phenotypic diversity of weedy red rice (Oryza sativa L.) in Arkansas, USA in relation to weed management. Crop Prot. 29:721-730.

Snow, A. A., Andersen, B., and Jorgersen, R. B. 1999. Costs of transgenic herbicide resistance introgressed from Brassica napus into weedy B. rapa. Mol. Ecol. 8:605-615.

Song, X., Liu, L., Wang, Z., and Qiang, S. 2009. Potential gene flow from transgenic rice (Oryza sativa L.) to different weedy rice (Oryza sativaf. spontanea) accessions based on reproductive compatibility. Pest Manag. Sci. 65:862-869.

Thurber, C. S., Jia, M. H., Jia, Y., and Caicedo, A. L. 2013. Similar traits, different genes? Examining convergent evolution in related weedy rice populations. Mol. Ecol. 22:685-698.
Thurber, C. S., Reagon, M., Gross, B. L., Olsen, K. M., Jia, Y., and Caicedo, A. L. 2010. Molecular evolution of shattering loci in U.S. weedy rice. Mol. Ecol. 19:3271-3284.

Valent, B., and Chumley, F. G. 1994. A virulence genes and genetic instability. Pages 111-153 in: Rice Blast Disease. R. S. Zeigler, S. A Leong, and P. S. Teng, eds. CAB International, Wallingford, U.K.

Vigueira, C. C., Olsen, K. M., and Caicedo, A. L. 2013. The red queen in the corn: Agricultural weeds as models of rapid adaptive evolution. Heredity 110:303-311.

Xu, X., Hayashi, N., Wang, C., Fukuoka, S., Kawasaki, S., Takatsuji, H., and Jiang, C. J. 2014. Rice blast resistance gene Pikahei-1(t), a member of a resistance gene cluster on chromosome 4, encodes a nucleotidebinding site and leucine-rich repeat protein. Mol. Breed. 34:691-700.

Zhang, W. Q., Linscombe, S., Webster, E., Tan, S., and Oard, J. 2006. Risk assessment of the transfer of imazethapyr herbicide tolerance from Clearfield rice to red rice (Oryza sativa). Euphytica 152:75-86.

\section{AUTHOR-RECOMMENDED INTERNET RESOURCES}

cM Converter: http://mapdisto.free.fr/cMconverter

Dryad repository:

http://datadryad.org/review?wfID=35709\&token=aab0eb0d-baef-4d98b09f-47be9473fdfb

Rice Genome Annotation Project:

http://rice.plantbiology.msu.edu/cgi-bin/gbrowse/rice/ 